\title{
Prison Subculture, Habitus and Adaptation; Tattooing in the Islas Marías, a Mexican Penal Colony
}

\author{
Nelson Eduardo Alvarez Licona*, María de la Luz Sevilla González \\ Instituto Politécnico Nacional, Mexico City, Mexico \\ Email: *nalvarez@ipn.mx
}

How to cite this paper: Licona, N. E. A., \& de la Luz Sevilla González, M. (2021). Prison Subculture, Habitus and Adaptation; Tattooing in the Islas Marías, a Mexican Penal Colony. Advances in Anthropology, 11, 76-98.

https://doi.org/10.4236/aa.2021.111007

Received: January 17, 2021

Accepted: February 23, 2021

Published: February 26, 2021

Copyright $\odot 2021$ by author(s) and Scientific Research Publishing Inc. This work is licensed under the Creative Commons Attribution International License (CC BY 4.0).

http://creativecommons.org/licenses/by/4.0/

\begin{abstract}
The Islas Marías are an archipelago formed by three islands and one islet, María Madre, María Magdalena, María Cleofas and the islet San Juanico, which are in the Pacific Ocean, 120 kilometers from the state of Nayarit in Mexico. Since 1905, the Islas Marías Federal Penal Colony was installed on the Isla María Madre as 9 camps around the island and one more in the center and ceased to be a penal colony in the year 2020. Life in this institution was regulated by the regulations of the institution and by the prison subculture, which governed the interaction between the inmates. In this type of institution, life took place between two perfectly established groups: the inmates (prisoners) and the staff (employees of the institution). The prison subculture, as a system regulating life among the prisoners, is explained to the extent that it is based on unformulated social agreements that are based on self-interest. These forms of belonging, built from the "we", in turn generate mechanisms of self-support that reinforce attitudes and behaviors. I propose that the practices that structure the prison subculture can be summarized as 1) Not denouncing. 2) Do not interfere in the affairs of others. 3) Showing courage at a given time. 4) In the male sexual character, which is present in the interaction between the inmates. In the Islas Marías, practices such as tattoos were carried out, which although prohibited by the institution's regulations, tattooing is very common in this place and is carried out in congruence with the prison subculture, being a practice that can be observed as a "habitus", understood as a practice that has the limits of its own conditions of production and of being the result of homologous practices, not being an obligatory practice, nor instituted, that is explained from conditioning stimuli that only act under the condition of finding again the already conditioned agents.
\end{abstract}




\section{Keywords}

Penal Colony, Prison Subculture, Habits, Tattoos, Knowing How to Throw

Time, Give and Take

\section{Introduction}

The Islas Marías Federal Penal Colony is an archipelago located in the Pacific Ocean, 120 kilometers from the port of San Blas in the state of Nayarit, in Mexico. It is composed of three islands and an islet that has the following dimensions in square kilometers: María Madre 144, María Magdalena 84, María Cleofas 25 and the islet San Juanico (or San Juanito) 8.53 kilometers. The penal colony is composed of 10 camps, which are located on Mary Mother Island, 9 of these on the periphery and one more in the center of the island, on the mountain.

The Islas Marías was a prison from which little was known, from which stories emerged referring to a place of violence and forced labor, a prison from which it was said: "from there you don't go back". They were an uncertain and unknown place, and around them, there have been woven a halo of mystery, having no more information than the brutality reported. For those of us who live in Mexico, the Islas Marías are something distant. We know they exist, but they seem strange to our experience, which we don't even consider, with a difficult geographical location, something dark, ethereal, but true. Like a sentence that no one would want to be imposed on (Figure 1).

The anthropological theory applied to this work, approaches the study from a series of theories that allow understanding the behavior of man, from a perspective that tells us about the reasons that make him carry out certain practices.

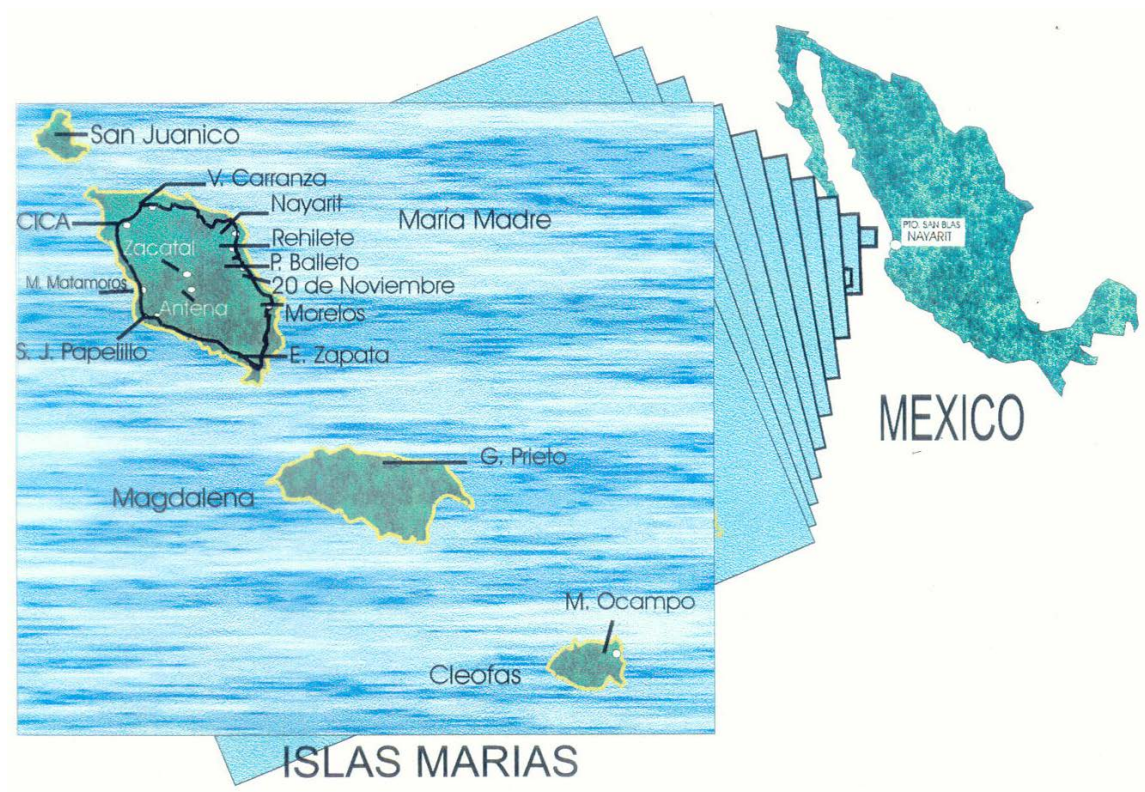

Figure 1. Map of the Isla Marías, Mexico. 
Studying the community through the information gives us an account of the way in which different cultural events are related. To explain some behaviors, they are studied from the theory proposed by Goffman (1992) to understand adaptation strategies in Total Institutions: García (1992) for studies of Territoriality, Bourdieu (1991) on the study of Abitus, Axelrod (1986) and Shalins (1977) for reciprocity studies. They are the lines of research that allow us to understand social practice not as a response of a uniform and homogeneous human conglomerate, determined and without the possibility of varying its behavior, but with its particularities that they show us diversity in homogeneity.

\section{Methodology}

The corpus of the investigation was formed with 30 open semi-directed interviews (approximately 45 hours recorded), which were agreed upon in advance choosing the informants who were: wives of settlers, settlers with family, single inmates (men), single inmates (women), camp leaders (employees). Those who lived in the penal colony without their family were considered Single Inmates. The informants were chosen to cover the greatest diversity in terms of the living conditions of the inmates, taking into account the following variables: sex, whether they were single or married (where it was taken into account whether they were living alone or with their family regardless of their marital status), their economic situation (here it mattered how they resolved their economic income, whether they obtained it from abroad or resolved it within the prison), the Camp Chiefs were interviewed regarding the characteristics of their camp as well as the strategies that the settlers used to obtain resources. The basic themes from which these interviews started were: daily life in the Islas Marías, arrival and departure from the institution by boat, obtaining resources, family participation, the obligatory work they call Melga, how to spend time in the confinement (throwing time away), violence, roll call, friendship, hierarchy among settlers. The themes of the interviews sought to be as open and general as possible so that the informant would be free to express his or her life stories in the least induced way. We did not always deal with all the topics and they were not dealt with in one order either, we had a list of topics with the points to be dealt with, trying to make sure that all of them were dealt with, putting the list together with the tape recorder in a clear way in front of the interviewee so that he/she could get used to being consulted, introducing the topics that were not dealt with when the silences indicated that the topic was exhausted, trying to intervene as little as possible, making comments on the topic in order to place the informant again in the conversation when we noticed that the silence denoted dispersion or that it took other directions. In these interviews, care was taken to find the most appropriate conditions for the informant to act naturally, ensuring the confidentiality of the data and looking for the most comfortable place for him/her, most of the interviews were done in the inmate's home or in his room, when there were other inmates in the room, the interview was postponed or was done in 
other places, which should not be too far away because the wait caused the informant to lose interest, the interviews should not be postponed for long because this made it lose spontaneity as the topics in one way or another were touched on in everyday conversations. The most important part for obtaining information consisted of the participant observation that took place in the Islas Marías Federal Penal Colony where we lived for a period of 8 months, 5 of which were in a punishment camp (Matamoros or Camarón) and practically isolated and together with the inmates. The spontaneous nature with which the information was obtained was due above all to the fact that we were able to maintain a respectful relationship with many of the inmates. This level of trust was achieved thanks to the fact that we did not work for the security department, in addition to the fact that we had all the time necessary to collect data, which was gradually corroborated as to its veracity as it was an integral part of the community being studied. Three one-month stays were carried out in 1996, also of one month, in which the interviews mentioned were made, we had already lived there for nine months, five of which in a punishment camp.

\section{The Prison Subculture}

We propose that the practices that structure the prison subculture can be summarized as 1) Not denouncing. 2) Do not interfere in the affairs of others. 3) Showing courage at a given time. 4) Sexual conduct that affirms the masculinity present in the interaction that takes place between inmates.

The Islas Marías were a mysterious place because of the unknown in which a halo of mystery was woven by not having more information, other than brutality by reference, in which the slightest comfort was evident, where distrust was of everyone and towards everyone, creating an atmosphere of anxiety that bordered on premature aging, while fearing the living and the dead. It was a place of hatred, betrayal and, exceptionally, of brotherhood, where each person saw for himself and friendship was the worst of deceptions, where sensitivity and brutality were opposed and violence was a daily occurrence, while life flowed slowly in a knowledge of how to waste time just waiting for the sentence to be served. Prisons are dark places, even when they are open to the sun's rays, like the Islas Marías. They are dark because they live in a world hidden from civil society, which allows for humiliating and degrading treatment under the cover of isolation that facilitates the formation of control zones where illicit businesses are frequent; The authorities are largely unaware of the daily life of the inmates inside the prison, due to the lack of interest in knowing and participating in the life of the prisoners, since their work is more about supervising the completion of sentences than about re-education, with social rehabilitation being the ultimate goal.

This lack of knowledge about the life of the inmates is also due to the difference that exists between the two groups that make up the life inside these institutions: inmates and staff (Goffman, 1992), where the differentiation of the two 
groups is made clear, mainly by the staff, to the extent that it was common in this penal colony for the employees in the Islas Marías to wear the uniform of the security personnel, even though they did not belong to this area, in order to make this difference clear, purpose of this was to provide security and to make clear the membership of the group they belong. This difference is also the result of the stigma attached to being identified as a member of the group of inmates, since people are categorized through the attribution of supposed characteristics, typical of the group to which they are assigned, which in the case of prison inmates, would be to receive the qualification of delinquents, badly living, which are profoundly discrediting characteristics that make them unworthy of trust, attributes that in turn affirm, by comparison, another set of characteristics for those who do not belong to the stigmatized group, leaving the employees within a supposed normality, which is not dishonorable and is a reference that in ethical terms, gives them an advantage over the group of inmates and justifies, from their perspective, the discriminatory treatment that occurs within this type of institution.

Inmates are a marginal group, since one is marginal to the extent that one is excluded from participation in certain areas of social life, which may be by decision or exclusion, since they do not form part of the roles that could be played; being marginal also means that it does not coincide with the valuation criteria that govern the agreed homogenization of men's behavior within the institutional prison culture; being marginal may be by its own decision, as it is the product of maintaining the criteria from which social practice is judged, or it may be marginal, as a result of the lack of participation of groups or individuals in the roles that would correspond to them, according to certain criteria of social organization; this lack of participation is sometimes forced, as in the case of imprisonment, leaving those who find themselves in this situation to share the interpretations of reality proper to these marginal groups that create them and recreate practices related to their conditions of existence: The Prison Subculture, as a series of practices that enter into congruence with a hostile and dangerous environment, to which the inmates adapt by making decisions that allow them to adapt in order to spend their time in prison.

In the case of the prison subculture we find the segregation of individuals, who due to their faults are in a marginal condition, those who are not important; which in turn implies the existence of forms of belonging developed as a marginal group, which are explained to the extent that they are supported by unformulated social agreements based on self-interest (García, 1992: pp. 400-411), thus the prison subculture is created from particular conditions of existence. These forms of belonging, built from " $w e$ ", generate mechanisms of self-sustainability that reinforce attitudes and behaviors. The marginal condition is associated with the lack of resources and means for subsistence, since in the Islas Marías for the majority of the inmates it was to live trying to resolve security and food, which in this respect part of it is provided by the institution, but it is insufficient and of poor quality. These social groups obtain the means that allow them to subsist, 
through low productivity and the use of objects that others no longer use, waste from industrial civilization, hence the characteristics of artisan production in the Islas Marías, where more than the use of industrial waste, natural resources are mainly used, although anything that can be useful and was very welcome to them, such as a spoon or a container where they can drink; Low productivity is a characteristic of production in this place, as well as marginality as a condition of existence in particular contexts. They maintain patterns of behavior that prevent them from adequately complying with the conduct that corresponds to them within what is established in these institutions, contradictions that are based on different social agreements and the prisoners are attached to both. In the prisons, people live within two norms and the workers of the institution know this and try not to interfere in the prisoners' affairs, unless this is in the interest of security and the general project of the institution, which is of the utmost importance. Inside the prisons there are regulations, criteria and norms that govern the conduct of the inmates and the personnel that work there and that are part of the institutional culture. Along with these social agreements, there is also a culture that subsists outside of what is permitted and that is governed by agreements of the Prison Subculture. The Prison Subculture has its own rules that are valid for the inmates, and together with the institutional ones, it regulates the way the inmates interact, allowing the integration or exclusion of the group, exclusions that could be very dangerous inside a prison.

\subsection{Non-Formulated Social Contracts}

Non-formulated social contracts are based on shared interests, which are only fulfilled by the collaboration of those who share the space (García, 1992: pp. 400-411) and it is from these agreements that we clearly see these rules, which have a moral and practical foundation: moral insofar as they are based on a group commitment that brings cohesion, by establishing normative obligations among the members; and practical, as it is a type of adaptive strategy based on the search for security, on knowing how to waste time. Respect for these informed social contracts facilitates a less conflictive interaction among the inmates and it is precisely the conflicts and tensions that reveal the importance of this type of agreement, which shows how normative the Prison Subculture is by mitigating the constant frictions that exist in these institutions. Failure to comply with this type of contract within a prison can be very serious, as would be the case if an inmate were to denounce to the authorities of the institution some infraction committed by another inmate, which would lead the denouncer to be considered a "chiva". Denouncing is permitted to an employee, but not to an inmate, who would not only be excluded from the clearly established social group, prisoners, inmates, but would also be subject to aggression and violence by other prisoners, which could even cost him his life, which is why these inmates are kept close to the staff. 


\subsection{Bravery, Non-Reporting, and Sexual Behavior that Affirms Masculinity}

Among the inmates, the conscience of a "we" is created, which in principle is given by the existence of the two groups present in all the total institutions, which are integrated by the inmates and the staff (Goffman, 1992: pp. 69-75), which creates a group conscience that does not guarantee cohesion in the case of the inmates. In the Islas María prison, the loyalty that should be generated by the group conscience was not very common, what deprived the loyalty was selfishness, especially in a prison where the lack of this characteristic was in fact one of the resources that the prisoners used as part of their knowledge of how to spend their time, is to be clear that inside the prison one is alone, that inside the prison one sees for oneself and the priority is to get out as best as possible; this is not in contrast to the idea of a " $w e$ " as a fundamental reference in the construction of identity, which is based on the differentiation that is very apparent between inmates and staff. However, the aspiration to have such loyalty was a constant within the prison subculture, only that it was continuously broken in practice, even though there was repeated mention of a "we" and a "they".

One of the causes of the breakdown of this loyalty declared in the discourse of the inmates, is related to the system of privileges that exists within the prisons, which makes the homogeneity, which in principle occurs in these institutions, fractured, since in these places there is a massive and therefore depersonalized treatment for the inmates, but in a place where lack is the norm, the slightest comfort is a highly appreciated good, privileges that would not be so if you were free, but within these institutions the possibility of talking on the phone, watching a movie, having access to buy fruit, eating clean and nutritious, receiving family visits, having a private space as a bedroom, etc., are a privilege, that is why the punishment camps in the Marías Islands, foster the punishment in isolation and lack of comfort. The constant reference to an $u s$ and a them in the inmates' discourse shows the existence of a series of characteristics or attributes shared by the group, these characteristics are acquired in principle by the fact of their being assigned as prisoners, but endorses the sharing or not of these cultural elements of the prison subculture. The location granted in principle by the institution is endorsed in the group itself, if the "conversion" (Goffman, 1992: pp. 69-75) is not taken as an adaptive strategy, becoming part of the other group, as is the case with snitches, informants or "chivas"; which show us the non-observance of these "non-formulated social contracts" (García, 1992: pp. 400-411) which are the basis of group solidarity and the norm that governs, to a large extent, the behavior of the inmates.

It is from these informed social contracts that we can observe the existence of a prison subculture whose purpose is to achieve goals, to the extent that it solves specific problems, by observing rules of behavior that influence the decisions that are made. The prison subculture expresses itself as group consciousness, maintaining the reproduction of cultural elements of collective identity and, from our perspective, it is explained by observing territoriality as a generator of 
conflicts. This is why seeing, hearing and keeping quiet is characteristic of the practice of men who see their security constantly exposed inside prisons; not participating in the conflicts that are generated in these spaces assures them a less dangerous stay, it is a matter of spending as little time as possible and in the best way possible in the confinement.

Not denouncing and sexual behavior that affirms masculinity, both are behaviors related to courage, which transgress sexuality considered normal and required in a space where the dispositions of the environment are first for the brave, homosexuality is frowned upon, that is why homosexuals are mistreated among the inmates, despite the fact that they constantly come to them for practice their sexuality. In reference to sexual behavior that affirms masculinity, the inmates who are most stigmatized and who are attacked are rapists, while those detained for murder are respected, as well as those who are imprisoned for drug trafficking, the use of narcotics inside the prisons is quite common. As prison is a space where lack abounds, inmates who steal inside the prisons are also very badly seen and may even risk their lives if they are caught stealing. Even those who do not defend themselves against the theft and abuse of other inmates show a lack of courage, of bravery, which is why it is very common for people to use violence to make their property and rights respected, delimiting in this way their territoriality, for example, within the corridor were established the spaces that belonged to them, and although they are very small, they are the places where they keep their belongings, these spaces are marked by means of personal objects and one even reaches the use of demarcations that make or are already in the physical space, frequently giving tacit agreements on the belonging of the spaces.

\section{Habitus and Tattoos}

In the Islas Marías the practice of tattooing was enriched by the arrival of "las cuerdas" (groups of prisoners) from the La Mesa prison, which is in Baja California, where the best tattooers come from, because in this prison the practice of tattooing is allowed, besides having the enrichment that comes from living near the houses that are dedicated to working the artistic tattoo in California. In the Islas Marías Federal Penal Colony, tattooing was prohibited, which was an obstacle for this practice to be carried out in hygienic conditions, in addition to continuing to enrich this artistic expression with better designs, since it was common practice for tattooers who were caught working to be punished, in addition to collecting their work instruments, along with magazines, embroidery samples and drawings where they fed their plastic ideas. But in spite of these impediments, tattooing nourished the prison subculture in the Islas Marías, existing in a vigorous way. It was curious to observe, when one is aware of the objective, a person eager to find drawings in magazines and books in the island's library, which was intended to support the educational system and which actually supports those who used it.

Despite the strict regulations, in the Islas Marias, inmates found a way to by- 
pass the institutional norms that regulated their conduct. This is why, in this place, where it was required to hide in order to get a tattoo, courage, clandestinity, the forbidden, risk, complicity and the reproduction of habitual behaviors and practices, are made in congruence with these agreements that we propose as a Prison Subculture and that exists outside of what is allowed, where the tattoo appears as an expression of other valorizations that regulated the life of the prisoners, to be tattooed in the Islas Marías, implied to penetrate the space of what is prohibited, but habitual within the prison subculture, and it is here where the cultural practices flourish that are shared by the participants in the tattooing process, participants also of this subculture.

Without a doubt, no one gives the chiva a tattoo, nor is she invited to see a tattoo done.

\subsection{Habitus}

We observe the practice of tattooing inside prisons as a "habitus", understanding the "habitus" as a practice coming from structures that have been maintained within a certain social group, due to conditioning associated with certain conditions of existence (Bourdieu, 1991: p. 92).

"The conditionings associated with a particular kind of conditions of existence produce 'habitus', systems of durable and transferable arrangements, structures predisposed to function as structuring structures, that is, as principles generating and organizing practices and representations that can be objectively adapted to their purpose without involving the conscious search for ends and the express mastery of the operations necessary to achieve them, objectively 'regulated' and 'regular' without being the product of obedience to rules and, at the same time, collectively orchestrated without being the product of the organized action of an orchestra conductor" (Bourdieu, 1991: p. 92).

The "habitus" understood in this way has the limits of its own production conditions and of being the result of homologous practices; the decision to tattoo is not the result of a forced or instituted practice, it is the result of a personal decision, which is induced by similar practices in particular conditions of existence, as it would be the tattooing inside a prison where approximately $75 \%$ of the population is tattooed. It is a particular decision that, although it results from socialization processes and sensitive experiences, is therefore particular. Although the construction of reality is in many aspects shared by the members of the same community or group, it is what gives meaning to $u s$, such as the idea of marginality that is created in people who have been imprisoned. Not because of this should the construction of reality be thought in strict terms of homogeneity, but as a result of "habitus" that have their origin in structures that tend to homogenize the construction of reality, but that are realized in the individual, so the "habitus" of tattooing oneself in this type of institutions is the result of homologous practices, without being the product of forced or instituted practices, 
that enter in congruence to of conditioning stimuli, that only act on condition of reencountering the already conditioned agents.

The practice of tattooing is particular to the practice itself, realizing itself in concrete beings in which their biography is present, their history objectified in fears, values, desires, pleasures and finally all the things that make us particular in our concretion of existence, independently of all the similarity that we are, we are particular stories, although similar in many aspects, particular as far as the concrete reality that we are. We understand the "habitus" as a result of the interrelationship that occurs between the reproduction of the regularities present in certain lifestyles and the present conditions that make men, at all times, making decisions. So, even though "habitus" are not original, they are particular as far as practice goes. In the interaction we learn and appropriate behaviors that are permitted and accepted in certain groups, the "habitus" are the product of the collective history that forms the objective references, those socially endorsed by a determined social group, that reproduce themselves in diverse forms maintaining in their foundation these elements of collective identity that make them characteristic of certain social groups, but that acquire particular forms in the measure that they are carried out by individuals in specific contexts.

"In reality, it is a relationship of homology, that is, of diversity in homogeneity reflecting diversity in the homogeneity characteristic of the social conditions of production, that unites the singular habitus of the different members of the same class: each individual system of dispositions is a structural variant of the others, in which the singularity of the position within the class and of the trajectory is expressed. The 'personal' style, of the particular brand that all the products of the same habitus, practices or works bear, is only a deviation from the style of a period or a class" (Bourdieu, 1991: p. 104).

\subsection{Habitus, Tattoos and Functional Efficiency}

The decision to get a tattoo within this type of institution is not an act that has as a purpose the achievement of some goal, but it is possible that the practice of tattooing obeys to the search of certain functional efficiency, like the one of marking oneself to be able to be recognized in a given moment. Based on the search of this efficiency, for example, a person who tattooed his blood type, in prevention of some accident or the intern who tattooed a card with an A and a $\mathrm{V}$, which are the initials of his name, thinking about the possibility that, if he suffered some accident or died, by means of this tattoo his mother could recognize him (Figure 2).

In the search of the functional efficiency, it is possible to find tattoos that have served of practice, while the skill is acquired, thus it is common that the tattooers are marked with unfinished drawings, abundant among these the very small tattoos, these are generally in the places that are facilitated to them to tattoo themselves, because at first the tattooers practice in their own body, reason why they 


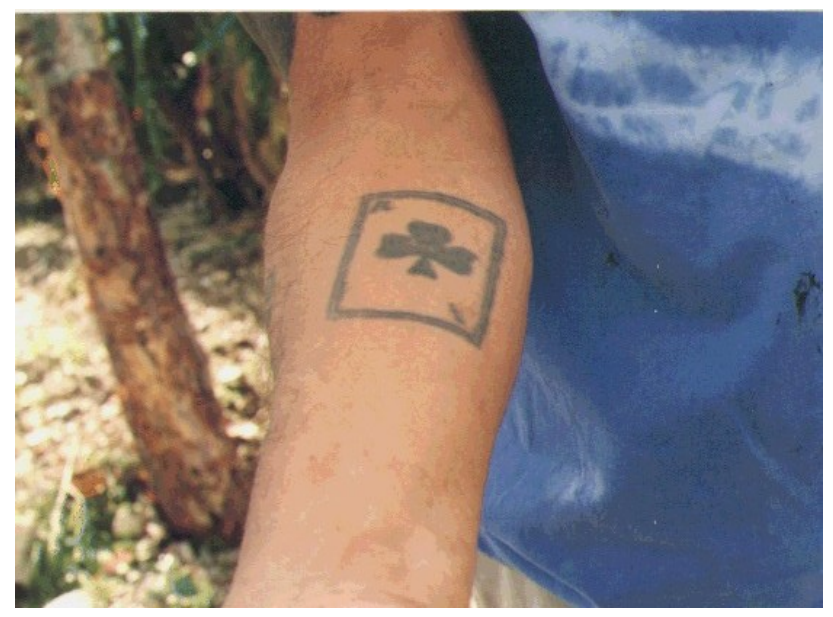

Figure 2. In search of efficiency, A and V tattoo.

predominate in the left side of the body, mainly in the arms and the legs, where in addition a badly made tattoo can be hidden. Also, in search of certain functional efficiency it was common to find small tattoos that are points or lines, that people made to see if the technique or coloring works, so it was common to observe in tattooed people a small test tattoo, next to their main tattoos.

It is also possible that the practice of tattooing can be present as a rite of initiation or as part of the agreement of a group that shares elements of identity, and even that tattooing is a form of strategy to which someone resorts to achieve greater acceptance by the group in which it is immersed or to which it seeks to integrate.

"It is by no means excluded that the answers of the habitus are accompanied by a strategic calculation that tries to consciously perform the operation that the habitus performs in another way, namely, an estimation of the probabilities assuming the transformation of past effect in the anticipated objective, these answers are defined in the first place outside of any calculation, in relation to objective potentialities, immediately inscribed in the present, things to do or not to do, to say or not to say, in relation to a probable future" (Bourdieu, 1991: p. 93).

The provisions for the habitus are given by Possibilities - Impossibilities. Freedoms and Needs. Facilities and Prohibitions. The Possibilities, are shown from the existence of tattooers, that are very easy to locate in this place where the best ones are identified and the tariffs are accessible and even, they are carried out as services that are interchanged and even when the tattooer's hand is warmed up. The Impossibilities are shown by the prohibition and with this the access to the appropriate technology for this practice, since in the Islas Marías it was difficult to be able to make a tattoo with different types of coloring, since this type of practice was prohibited since the authorities of the institution did not allow the entrance to this prison of coloring that could be used for the inmates to tattoo themselves, neither did they allow the introduction to the penal colony of specialized magazines about tattooing, which affects the type of graphics that were tattooed inside this prison. Freedoms, which are given based on the 
prison subculture that protects and makes possible this type of habitus, in such an effective way that it made very little effective the prohibition of the institution with respect to the practice of tattooing inside the Marías Islands. Needs, which promoted this practice since it is precisely from their work that the tattooers obtained the resources for their subsistence, in a place where it was very difficult to sell the labor force or generate economic resources. Facilities, given both by the prison subculture and by the very economic prices could cost the realization of a tattoo, a tattoo of approximately $5 \mathrm{~cm}$. of diameter, the equivalent to the price of a medium instant coffee bottle; although in many occasions the cost of a tattoo was given by another type of interchange, in which the proximity in terms of friendship or kinship influences, being able to exchange a tattoo work for clothes, cigarettes or some services; and even not costing anything in a determined moment, when the tattoo session acquires such intensity that they are more tattooed than expected, it is said of this type of sessions that the tattooist had his hand warmed up. Prohibitions, as far as the prison subculture is concerned, it is said that an informer, chiva, is neither painted nor invited to see a tattoo, besides being a practice that was prohibited by the prison institution.

\section{Adaptation Strategies in the Practice of Tattooing in the Marías Islands}

The practice of tattooing within this institution can be observed as a strategy of "Give and Take" (Axelrod, 1986) as a form of adaptation within the Islas Marías, since it is from the balanced exchange (Shalins, 1977) that the tattooers through their work obtain the resources for their maintenance. In the exchange, tattooers and tattooed men are constantly faced with the cooperation of other prisoners, since in this practice we find present phenomena of collective identity of the inmates that are typical of the prison subculture, such as: not denouncing, not interfering in other people's affairs, courage, sexual conduct that affirms masculinity; which are not formulated social agreements (García, 1992: pp. 400-411) and since it was forbidden to tattoo, it requires hiding and complicity, cooperation in order to be carried out.

Cooperation is based on reciprocity, in which a balance is sought between what is invested and what is obtained from what is invested, and a proportional relationship is expected. In this place, as the economic resources were very scarce, the exchanges took place without the strict mediation of money, although the tattooers had established the price rates for the accomplishment of their work, these very economic what acted as facilities, being part of the structuring structures that allowed to maintain the practice. Thus, cooperation allows for a form of "give and take" exchange, in which immediate compensation is not required, although it is expected, and the return of the goods or favors given is established as a commitment, which is very feasible in these spaces, since within the prison there are real expectations of continuous and prolonged interaction between the inmates. However, we should not think that the inmates, just be- 
cause they are inmates, interact in terms of cooperation; cooperation as a form of exchange is influenced by the degree of kinship and friendship, which forces the return of what has been received to the extent that the proximity of kinship and friendship is distanced (Shalins, 1977). Being security one of the main problems of the inmates, it forces cooperation that is supported as needs, possibilities, liberties and facilities, in the social contracts not written or tacitly agreed upon, which does not mean that the inmates will constantly cooperate with each other in their interaction, in fact cooperation is not given from a group conscience with a moral foundation as the main reason, it is given for reasons of convenience, so that the own interests that appear as common interests can be fulfilled. Cooperation is based on the sharing of common interests, which are explained by self-interest. Since the practice of tattooing is based on the need to obtain resources, which, together with security as a priority within the Islas Marías, as well as cooperation based on undeclared agreements that allow this practice to take place, we find tattooing as an exchange strategy that is carried out in a non-conflictive integration between the inmates, which entails elements of collective identity, supported by the prison subculture.

If the collective identity begins with the affiliation to the same institution, where there are two perfectly differentiated groups: inmates and staff (Goffman, 1992: pp. 69-75); this affiliation is sustained, on the part of the inmates, to the extent that the phenomena that make up the prison subculture are maintained and respected. Thus, the fact that many inmates (approximately 75\%) decide to get a tattoo reproduces elements of collective identity that are specific to the social group, and insofar as the practice of tattooing reproduces and maintains habitus, it is part of a knowledge of how to waste time, which as an adaptation strategy tends towards "colonization" (Goffman, 1992: p. 71), allowing the inmate, to a certain extent, a better integration to the prison subculture that he or she shares, reproduces and within which it would be very dangerous to be excluded. Thus, this practice responds to and maintains the structuring structures that are typical of the living conditions of the inmates.

Tattooing in the Islas Marías was not a conscious goal, although sometimes it was, nor was it the result of established rules, since it was part of an understanding of reality from a certain homogeneity resulting, in part, from this type of structure that is preserved over time thanks to the practice of individuals, who by carrying it out, keep it vigorous and present, The aim of this project is to promote the construction of reality in groups that share particular conditions of existence, from which we can see identity as a construct in which it is shown how the inmates interpret reality and respond to the alternatives, sometimes in an unconscious way, that are given to them in the social contexts, from which they shape their interpretation of reality.

\section{The Process of Tattooing in the Marias Islands}

The most common tattooing technique within the Islas Marías was the puncture 
or stinging, although within the prisons the technique of incision or "sajadura", carried out with razor blades, is used; In the Islas Marías a settler brought a series of scars on his arm made by means of incisions or "sajaduras", made with a razor, in a competition to show who was braver by making more cuts (sajaduras) with the razor (Figure 3), those who were participating acted in congruence with these agreements, the Prison Subculture, where bravery must be shown at all times, one of them made cuts from the shoulder to the wrist.

The instruments that were used to tattoo in the Islas Marías were made by the same inmates and it was a pen that has as a spare a guitar string, that penetrates and leaves the skin driven by a small motor, helped by a current transformer; this device is connected to the electric current, but generally used with batteries; this together with some Indian ink, joined to the dexterity and imagination, conforms the necessary elements of the tattooist. Some first draw the tattoo on the skin or copy the drawing, the most used technique to copy the design on the skin is to draw on a paper and on this one you put bar deodorant, the same is done on the place where the tattoo will be, you put the drawing pressing it on the skin and it is marked; Other tattooists, the most expert and skillful, tattoo directly, copying from their worn and wrinkled samples, magazine clippings, embroidery samples or drawings made by them; there are tattooists who pour their imagination directly when they are tattooing. Within the prisons the obtaining of colorants is very difficult, especially in those where tattooing is forbidden, so the most unheard of materials are used, a resource to which those who want to get a tattoo and do not have colorants used in these prisons, is to obtain pigments from the combustion of rubber or plastic, which they obtained from the rubber sole of their shoes or from razor blades that have a plastic sleeve. The soot smoke that arises from the combustion is captured and mixed with hair soap, thus obtaining a paste that they use as a colorant; obtaining dye

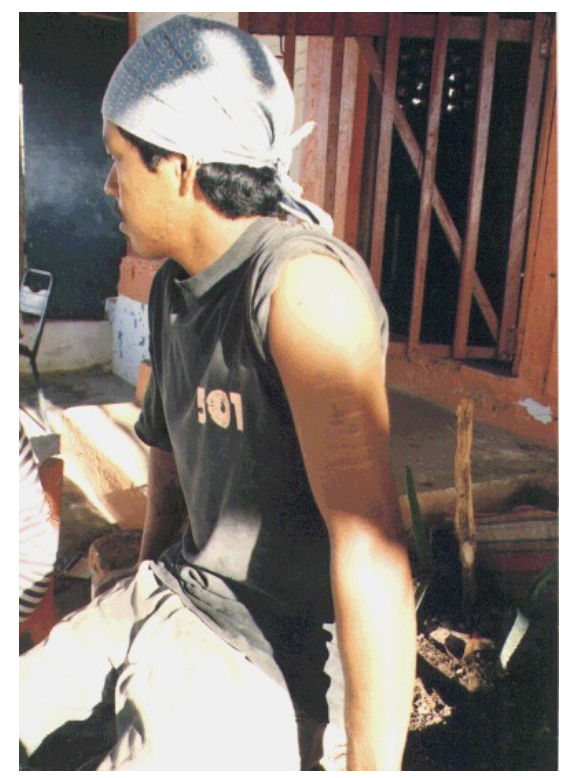

Figure 3. Tattoo of sajadura in the Islas Marías. 
by this method is also used inside other prisons; when I asked a person, who got a tattoo inside a prison in Spain, he answered:

- With what did they make it for you: "With ink from (pointing to the rubber sole of your shoe), it burns not, it makes smoke, smoke that stays trapped in a plate, then you pour a little bit of shampoo (soap) and you make a paste, and that paste you put it on".

The use of pigments obtained from the combustion of rubber is frequent in the prisons of Spain. Dr. Font Riera (1972), in the survey he conducted on 100 prisoners, records that 54 had used this procedure to obtain the dye. This is because the prohibition to tattoo makes it difficult to obtain Indian ink. Among the data obtained in his survey, he records that:

"Apart from the use of Indian ink and the soapy composition of carbon black, we must point out for the color black, giving it a more exceptional category, the following substances: carbon dust, soot dust, smoke dust from burned oil, smoke dust from burned plastic, ink from pen. As for the color red, it has been achieved: in 18 cases using brick dust, in 2 cases with watercolor paint of this color, in 2 cases with Indian ink, in 2 cases with redcurrant" (Font Riera, 1972: p. 14).

Tattoos on the Islas Marías were generally painted with navy blue Indian ink, which it is possible to get within the penal colony as they obtain it from pens. Less frequent was the use of red ink, because it was not always available and it was necessary to go over the tattooed area at least three more times. The tattooing process starts with the decision to get a tattoo, and then choose what to mark. The possibilities present in the samples are reviewed, on which different opinions are poured among those who participate in the process, although there are those who arrive with the drawing already chosen, designed or just the idea. The next step is the sterilization of the needles, which are pieces of sharp guitar strings, by first disassembling the machine and then introducing the needle directly into the fire of a match or a lighter until it reaches a glowing red that ensures sterilization. Afterwards, the skin that is going to be tattooed is prepared, cleaning the region where the tattoo is going to remain, trying to disinfect it when there is a possibility of getting alcohol or a lotion, which is quite difficult, since the regulations of the prison did not allow the introduction of these products, In the absence of this, the region to be tattooed is cleaned with a little cooking oil, there have been many cases of infection and even hepatitis caused by lack of hygienic conditions, even the possibility of catching HIV/aids is feasible in the practice of tattooing in unhealthy conditions. Then, the hair is shaved, because the hair and sweat makes the work more difficult and makes the possibility of an infection more feasible. To solve the problem of sweat, small portable fans were used to keep the skin a little cooler, especially in a place where the temperature in the environment is always very high, in summer it reaches 40 or more degrees in the shade. Tattooing here was done without the use of anesthetics, not only because of the lack of these, but also because of the constant refer- 
ence to the courage in the interaction of the inmates, typical of the prison subculture.

Once installed the one that is going to be marked, the tattooist begins the drawing, as he is tattooing the pain with which the session begins is fading and as if the reddened and hot skin accepted to be marked, it allows the tattooist's needle to run more freely, while he discovers the traces cleaning the blood that flows from the tears. We had been looking for a good tattooist to paint us, so we had asked the "Chino", who was an intern friend of ours, to locate the "Pollo", because we knew he was one of the best tattooers. It was the afternoon when the "Chino" arrived with the news that it was already fixed, so we went to the barracks where the "Pollo" was, when we approached him we told him that we wanted to get tattooed, he was surprised as if he had not been told already, the prohibition to get tattooed inside the prison made us understand his strangeness and distrust, what was strange is that an employee wanted to get tattooed, however what surprised him at first, later became an identity element that allowed a pleasant interaction between tattooist and tattooed; He told us that he did paint us, that we should wait for him while he picked up his things, and he went into his hut for his tool; With his tools we went to the "Primero de Mayo" colony, where we had lived for the last 3 months. When we arrived, the person in charge of the surveillance of the residential area approached us, who was another intern expert in martial arts, with two beautiful dragons tattooed on his forearms, Since inmates are not allowed to enter this area of employee housing, as this guard was known to us we told him we were going to get tattoos, to which he responded that he would warn if security people arrived, in this identity built from us, where the prison subculture guided the actions; We entered the house so that he could tattoo us, and while he was taking out his instruments that he had in a small and dirty cloth bag, the possibility of an infection passed through our minds, from his bag he took out an electric needle made by him and a bottle of Indian ink. He asked us for some alcohol or a lotion, and since we didn't have any of that, he cleaned the needle with cooking oil, the same as the area he was going to tattoo, and since we didn't have any cotton or gauze either, he cleaned the area with toilet paper. He poured some Indian ink into the lid of the same bottle, connected his tattoo machine to the electric current and was ready to start the tattoo. We had told him that we wanted a ribbon, which is a type of tattoo in which a dense bouquet of flowers is made and underneath it a ribbon comes out, on which a name is placed; once we indicated the place and the extension that we wanted the tattoo to have, without more and without making a previous drawing, the tattooist attacked the area starting with the main flower in the center, to make it grow as it adds petals; The first tears are painful and as the pain advances it becomes more bearable, as if the skin accepted to be marked; as the line advances, the tattoo must be constantly cleaned, because it is quickly covered with blood with ink, that first in continuous form, later in threads and then in drops it sprouts by the wounds, it is as if the skin cried; Once he outlined the first flower, he drew another one, and another one that he left as a button, 
and then he sowed leaves around the flowers; then he made the undulating ribbon come down and end up being twisted, on which he wrote Lucy's name, enriching the whole with leaves and undulating lines that increased the movement of the tattoo and made another flower sprout that was trapped between the ribbon and the main flower; With all this he began to put shadows that were giving depth to the drawings, making the process painful, because when the tattoo is shaded it is reviewed several times on the same wounds that continue to bleed and you have to clean them constantly to see what areas need to be reviewed.

The result was an exquisite ribbon that unrolls and comes down from a bouquet of flowers coiled in itself, where its spiral unfolds in an inexhaustible moment, in which time has ceased to exist, because it is always about to stretch completely and does not achieve it (Figure 4).

The process was very rich and intense in participation, because as he was drawing, we agreed on the details he was adding, so that the result was a tattoo made by the three of us, in a communion of interests and feelings that came out in the form of a beautiful tattoo. The session lasted approximately two hours. When the tattoo was finished, the blood that at first came out abundantly and then in continuous drops, stopped, when he made the last cleaning and we could see the complete tattoo, it had been left on an extremely irritated, hot and painful skin. During the first hours, even the friction of my skin with the fabric of the shirt was annoying. In the beginning the tattoo was discolored, with time and as the abused skin was peeled off it took on more color, and all that was left was to take care of the tattoo with much hygiene to avoid possible infections; a severe skin infection, apart from the understood biological consequences, can bring about that the tattoo becomes deformed forever and thus instead of having given birth to a beautiful feeling, give rise to a monster. In three days, the skin had regained its characteristics, only now engraved with our tattoo. The cost of the

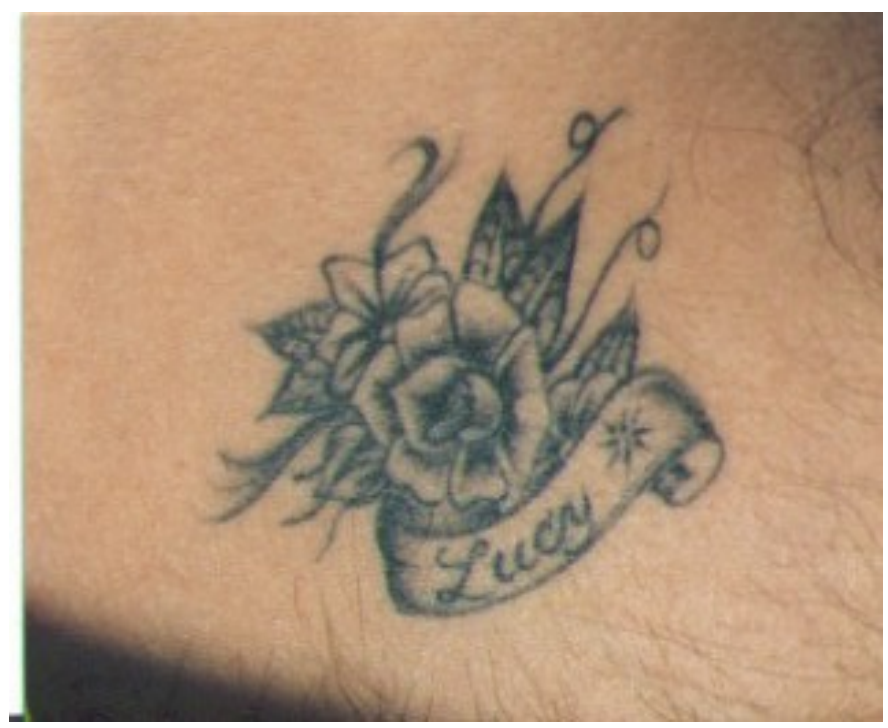

Figure 4. Flower tattoo in the Marias Islands. 
tattoo was the equivalent of half the price of a bottle of instant coffee. The immediate recommendation for those who have been tattooed, is to apply cream or oil to the mistreated skin, which remains very sensitive and red during the first days and which dries and peels off, so that with time and some care it will take on its original characteristics again, only now already marked. In the case of the tattoos we had done, the needle was not sterilized, and since we were not aware of the fire sterilization, it did not occur to us either, but we have been in other tattooing sessions, and in these we have seen the sterilization of the needle by this means.

The tattooing process in the Islas Marías took place in sessions that combined hiding, complicity, cooperation, courage and a special atmosphere created by the group, where there is no lack of a joint (marijuana cigarette), which shows the structures on which the prison subculture is based. These meetings become very intense and those who do not watch, comment, give their opinion, prepare the "porro", tattoo or are being tattooed, interspersed with moments of silence in which everyone is attentive to the tattoo that is covered in blood and paint; In that environment that says that the guy's hand got warm and the meeting results in more tattoos than they thought, because not only the tattooist has a warm hand, but the participants also got warm; in the tattooing sessions that come to have this intensity, the role that money has as a mediator of the exchange, occupies a secondary place. In the Islas Marías it was common to find people tattooed from the neck to the feet, trying to balance their tattoos by putting them, an equal devil on each thigh, two identical skulls on the forearms, on one chest a dense bouquet of flowers and on the other two intertwined hearts crossed by an arrow and in the middle the name of a woman; it was difficult to observe a drawing that covered the whole body or a large part of it, except in the case of virgins or christs that occupy the whole chest or the whole back. The way tattoos were created in this place is through drawings that are not very big, that gradually take possession of the body, except for the face, where if they are tattooed, very delicate drawings are painted as small tears (Figure 5).

Many of the tattoos, especially the big ones, have to be done in parts, because the pain and irritation to which the skin is submitted becomes so severe, that it makes impossible that in a single session the whole process is carried out, so it was very common in this place to observe half-finished tattoos (Figure 6). We saw a virgin whose silhouette had just been born and which occupied the outline of a muscular back, which could not finish emerging, until the effects of the first session had subsided, as the irritation was so great that a minimum of a week's rest would be required, in order to continue the work.

Walking down any street in the Islas Marías was an interesting experience, you could see tattoos sticking out of your arms, shoulders, neck, feet or anywhere else. In this place it was common to find christs and virgins, like devils and skulls, being the most common tattoos, along with terrors, women, names and dates, although you could find anything marked on the skin. People boasted 


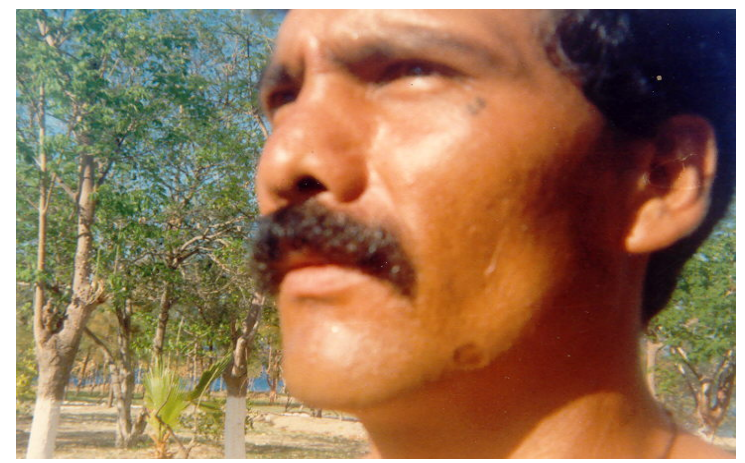

Figure 5. Tears, Islas Marías.

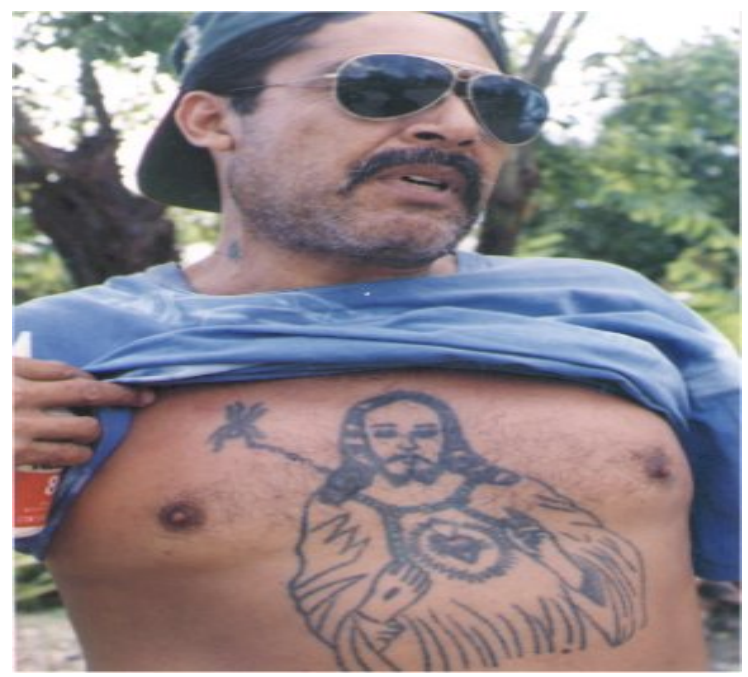

Figure 6. Christ on the chest, Islas Marías.

of bringing original drawings, being able to appear when turning the corner to King-Kong trapped in a chest or a hand covered by a spider's web, characters alluding to marijuana were frequent and appeared tattooed characters holding a joint, on the back, on the legs or anywhere else; There was no lack of a morphine harpoon or a mushroom decorating those who had had the experience; as well as tattoos alluding to the sea were frequent, so anchors, sienna and sharks were frequent in this place; the tattoos of women, everywhere precisely because of their absence, being the heterosexual practice what is most missed and desired in the confinement, the tattoos of beautiful women who tenderly embrace a shoulder, sensual women who overflow their hair on one arm, mermaid women, obscene women, naked women, half-naked women, hidden in a veil, charras women wearing a wide-brimmed hat, demon women with skulls on their faces and another devil on their pubes, but women, always women; the tattoos of devils are impressive and many of them manage to capture evil, ferocity and irony in their grimaces, while showing their drooling tongue, fixing their penetrating eyes injected and crowned by twisted horns, catrine devils that with their clothing do not hide their evil, naked devils with long tails, smiling devils, but never innocent devils; we saw a devil that fornicates with a woman, when the tattooed 
one moved his biceps (Figure 7).

A tattoo that tears the conscience is the beautiful MOTHER MY, that as a pleading cry reminds her from the deepest place of the prison, wrapped between roses like a virgin, is one of the most beautiful tattoos of the Marías Islands.

With a magical sense of protection that we saw in the Islas Marías, it was a tattoo that was painted on a settler, who has The Sword of Retirement tattooed on his right arm, which hanging from a hook is held in a winding belt, from which two tassels hang at its ends; this defending tattoo removes from the one who carries it, the lurking danger, the terrible company that is bad luck, envy and bad influences (Figure 8). In the Market of Sonora, in Mexico D. F., we find the print of "The Sword of the Retreat", accompanied by an incense that burns while this prayer is invoked:

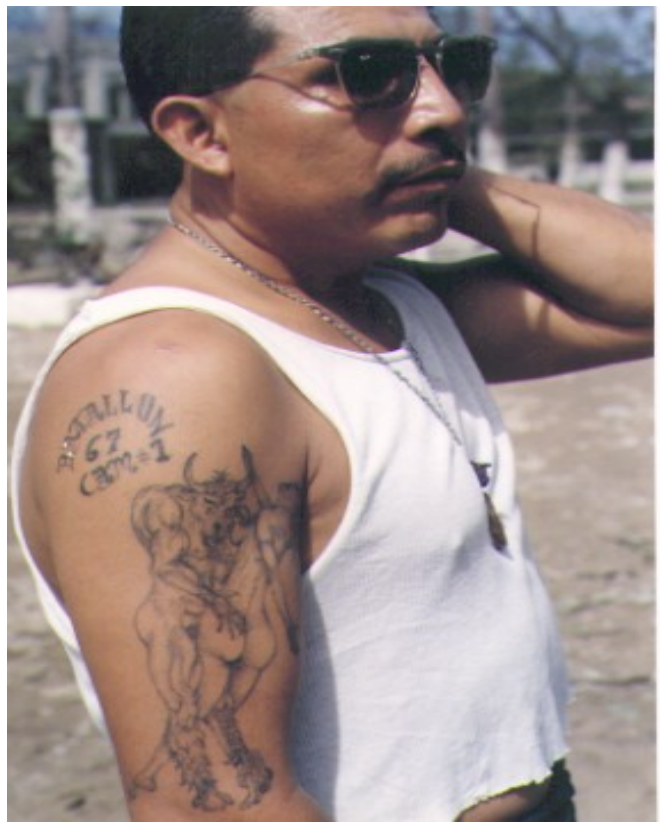

Figure 7. Devil with a woman, Islas Marías.



Figure 8. Protective tattoo: The sword of Retiro, Islas Marias. 
"House of Jerusalem, where Jesus Christ entered, evil to the point of coming out at the same time as good, I ask Jesus also, that evil may go away from here, and good may come to me, through this incense. Amen”.

The old "pintos" know that whoever gets out of prison should not take anything with him, except the clothes he is wearing, and when they leave the prison, they throw them away or burn them. They also say that when someone leaves the islands free, he should not look back as he crosses the pier to board the boat, because whoever looks back, returns. Prisons are known as "pints", this is because it is very common in these places for people to get tattoos.

Nothing they would like to take with them, but the indelible memory will accompany them throughout their lives, just like their tattoos that were made inside the Islas Marías, the only memory that is worth keeping and that will be proudly displayed as it shows, as in the case of the old sailors, the proof of their stay in strange places.

\section{Conclusion}

The study of territoriality in the Islas Marías penal colony, shows us how the control of space source of conflicts is, in turn, a force of social cohesion, which ascribes people to the territory where they are linked, producing a type of identification to the sharing particular interests, which appear as group interests; and that are based on "informed social contracts" that are established based on particular objectives, which cannot be fulfilled without the collaboration of those close to them (García, 1992).

The Adaptation Strategy of "Give and Take" (Axelrod, 1986) is based on equitable reciprocity in which it is expected to recover what is invested, and we find it present among the settlers of the Marías Islands. Life inside this prison occurs between two norms: the one that comes from the institutional culture and the prison subculture, which is generated according to the particular conditions of existence.

The Prison Subculture is based on Informulated Social Contracts, which in turn are based on shared interests among those who share the space. These contracts have an ethical and practical foundation: ethical as it is a group commitment that unites the members and practical, as it is part of adaptation strategies, in which Safety is sought; allow a non-conflictive interaction between the inmates, so that this type of social contracts is the support of the solidarity that exists between the inmates, creating the consciousness of a "we", not being loyalty, but interest, which is at the bottom of the cohesion that exists between the inmates. These types of non-formulated agreements seek to achieve goals and allow the resolution of specific problems, by respecting the rules of behavior typical of the prison subculture, which can be summarized as: 1) Do not report. 2) Do not meddle in other people's affairs. 3) Show courage at a certain time. 4) In the male sexual character, which is present in the interaction that occurs between the inmates. 
The study of the practice of tattooing should be done from case investigations. For this, we propose that studies be carried out from the construction of adaptation and the construction of identity; and not from the classification of the spellings, as had been done, since this type of study ignores the reasons that precede tattoos, which find their explanation in the society where they are generated. Studying the man and not the spelling, allows the reasons that give rise to tattoos to emerge, which have to do with the interpretation that we make of reality at all times, regardless of whether this interpretation is made from scientific knowledge or from the mythical interpretation of reality, in order to understand society as a generator of culture, at the same time that it shows us the man who is at all times before decision-making.

The practice of tattooing in the Marías Islands is a habit that comes from structuring structures that arise from conditions associated with particular conditions of existence. It is a practice that does not imply the achievement of an end, or the obedience of rules, but it is the product of a collective history that is perpetuated over time; these practices are induced by similar practices. The practice of tattooing is not mandatory and is part of the common sense of the inmates, which means that the practice of tattooing, even though it is not intended to achieve an end, allows a better integration into the social group. Getting tattooed in this prison results from balanced reciprocity relationships, this is why it can be studied as "Give and Take" strategies, since it is from this type of exchange that tattoo artists obtain their financial resources.

Getting tattooed in the Islas Marías federal penal colony has to do with:

- With the prison subculture that the inmates reproduce and maintain in practice.

- With practices typical of social groups, which involve elements of social identity.

- With habitus, those that are associated with particular conditions of existence.

- With objective conditions such as: possibilities, freedoms, needs, facilities.

- With homologous practices, which reproduce regularities present in certain lifestyles, which are maintained over time and are based on past experiences.

- With diversity in homogeneity.

- With the image that we have and that we try to show, in this we recognize ourselves in a "we".

- With personal history, with biography.

- With adaptive strategies that allow a better integration into the prison subculture, facilitating its adaptation to the environment, through colonization.

- With the interaction that occurs between the interns, based on balanced reciprocity, which is manifested through the strategy of give and take.

- With decision-making in which it is thought that this form of identification can serve personal interests at a given moment.

- With the search for a certain functional efficiency.

- With a mythical way of understanding reality, protecting itself through brands. 
- With aesthetic forms that we are acquiring socially.

- With identity, understanding it as a state of reality, as a construct, as something never finished and in constant transformation, a product of the formalization that we make of reality.

\section{Conflicts of Interest}

The authors declare no conflicts of interest regarding the publication of this paper.

\section{References}

Axelrod, R. (1986). La evolución de la cooperación. Madrid: Alianza Universidad. Bourdieu, P. (1991). El sentido práctico. Madrid: Taurus Ediciones.

Font Riera, G. (1972). Tatuaje y Delincuencia. Barcelona: Resumen de tesis presentada para aspirar al grado de Doctor en Medicina.

García, J. L. (1992). El uso del espacio: conductas y discursos. en J. A. Glez Alcantud y M. Glez de Molina (Eds.); La Tierra: mitos, ritos y realidades. Barcelona: Anthropos.

Goffman, E. (1992). Internados. Buenos Aires: Amorrortu editores.

Shalins, M. (1977). La economía de la edad de piedra. Madrid: Akal. 